\title{
Burden, access, and disparities in kidney disease
}

\author{
Deidra C. Crews M.D. ${ }^{a, b, c}$, Aminu K. Bello PhD and M.D. ${ }^{d}$ and Gamal Saadi M.D. ${ }^{e}$, for \\ the World Kidney Day Steering Committee. ${ }^{f}$
}

\author{
a. Division of \\ Nephrology, \\ Department of \\ Medicine, Johns \\ Hopkins University \\ School of Medicine, \\ Baltimore, Maryland, \\ USA. \\ b. Welch Center \\ for Prevention, \\ Epidemiology and \\ Clinical Research, \\ Johns Hopkins \\ Medical Institutions, \\ Baltimore, Maryland, \\ USA. \\ c. Johns Hopkins Center \\ for Health Equity, \\ Johns Hopkins \\ Medical Institutions, \\ Baltimore, Maryland, \\ USA. \\ d.Division of \\ Nephrology \\ \& Transplant \\ Immunology, \\ Department of \\ Medicine, University \\ of Alberta, \\ Edmonton, Canada. \\ e. Nephrology Unit, \\ Department of \\ Internal Medicine, \\ Faculty of Medicine, \\ Cairo University, \\ Giza, Egypt. \\ f. See Appendix for list \\ of members of the \\ World Kidney Day \\ Steering Committee.
}

E-mail address:

Deidra C. Crews:

dcrews1@jhmi.edu

Funding:

None.

Conflict of interest:

None.

Received: 2-11-2019

Accepted: 2-19-2019

\section{ABSTRACT}

Kidney disease is a global public health problem; affects more than 750 million persons worldwide. The burden of kidney disease varies substantially across the world, as does its detection and treatment. Emerging evidence suggests that developing countries have a similar or even greater kidney disease burden than developed countries.

In many settings, rates of kidney disease and the provision of care are defined by socioeconomic, cultural, and political factors, leading to significant disparities, even in developed countries. These disparities exist across the spectrum of kidney disease -prevention, screening, care and treatment. World Kidney Day 2019 offers an opportunity to raise awareness of kidney disease. This editorial highlights these disparities and emphasizes the role of public policies and organizational structures in addressing them. We outline opportunities to improve our understanding of disparities, the best ways to address them, and how to streamline efforts toward achieving kidney health equity across the globe.

Key words: acute kidney injury; end stage renal disease; global health; health equity; social determinants of health.

http: / / dx.doi.org/10.5546/ aap.2019.eng.e243

To cite: Crews DC, Bello AK, Saadi G. Burden, access, and disparities in kidney disease. Arch Argent Pediatr 2019;117(3):e243-e251.

This article was published in Kidney International volume 95, pages 242248, Copyright World Kidney Day 2019 Steering Committee (2019). The article reprinted concurrently in several journals. The articles cover identical concepts and wording, but vary in minor stylistic and spelling changes, detail, and length of manuscript in keeping with each journal's style. Any of these versions may be used in citing this article.

\section{INTRODUCTION}

Kidney disease is a global public health problem that affects more than 750 million persons worldwide. ${ }^{1}$ The burden of kidney disease varies substantially across the world, as does its detection and treatment. Although the magnitude and impact of kidney disease is better defined in developed countries, emerging evidence suggests that developing countries have a similar or even greater kidney disease burden. $^{2}$

In many settings, rates of kidney disease and the provision of its care are defined by socioeconomic, cultural, and political factors, leading to significant disparities in disease burden, even in developed countries. ${ }^{3}$ These disparities exist across the spectrum of kidney disease -from preventive efforts to curb development of acute kidney injury (AKI) or chronic kidney disease (CKD), to screening for kidney disease among persons at high risk, to access to subspecialty care and treatment of kidney failure with renal replacement therapy (RRT). World Kidney Day 2019 offers an opportunity to raise awareness of kidney disease and highlight disparities in its burden and current state of global capacity for prevention and management. 
In this editorial, we highlight these disparities and emphasize the role of public policies and organizational structures in addressing them. We outline opportunities to improve our understanding of disparities in kidney disease, the best ways for them to be addressed, and how to streamline efforts toward achieving kidney health equity across the globe.

\section{Burden of kidney disease}

Availability of data reflecting the full burden of kidney disease varies substantially because of limited or inconsistent data collection and surveillance practices worldwide (Table 1). ${ }^{4}$ Whereas several countries have national data collection systems, particularly for end-stage renal disease (ESRD) (e.g., United States Renal Data System, Latin American Dialysis and Renal Transplant Registry, and Australia and New Zealand Dialysis and Transplant Registry), high-quality data regarding nondialysis CKD is limited, and often the quality of ESRD data is quite variable across settings. This situation is of particular concern in low-income countries. For example, a meta-analysis of 90 studies on CKD burden conducted across Africa showed very few studies (only $3 \%$ ) with robust data. ${ }^{5}$ The provision of adequate resources and a workforce to establish and maintain surveillance systems (e.g., screening programs and registries) is essential and requires substantial investment. ${ }^{6}$ Incorporating kidney disease surveillance parameters in existing chronic disease prevention programs might enhance global efforts toward obtaining high-quality information on kidney disease burden and attendant consequences.

In addition to a need for functional surveillance systems, the global importance of kidney disease (including AKI and CKD) is yet to be widely acknowledged, making it a neglected disease on the global policy agenda. For instance, the World Health Organization (WHO) Global Action Plan for the Prevention and Control of Non-Communicable Diseases (NCDs) (2013) focuses on cardiovascular diseases, cancer, chronic respiratory diseases, and diabetes but not kidney disease, despite advocacy efforts by relevant stakeholders such as the International Society of Nephrology and the International Federation of Kidney Foundations through activities such as World Kidney Day. This situation is quite concerning because estimates from the Global Burden of Disease study in 2015 showed that around 1.2 million people were known to have died of CKD, ${ }^{7}$ and more than 2 million people died in 2010 because they had no access to dialysis. It is estimated that another 1.7 million die from AKI on an annual basis. ${ }^{8,9}$ It is possible, therefore, that kidney disease may contribute to more deaths than the 4 main NCDs targeted by the current NCD Action Plan.

\section{Risk factors for kidney disease}

Data in recent decades have linked a host of genetic, environmental, sociodemographic, and clinical factors to risk of kidney disease. The population burden of kidney disease is known to correlate with socially defined factors in most societies across the world. This phenomenon is better documented in high-income countries,

TABLE 1. World Bank country group chronic kidney disease gaps

\begin{tabular}{|c|c|c|c|c|}
\hline CKD care & $\begin{array}{c}\text { Low-income } \\
\text { countries } \\
(\%)\end{array}$ & $\begin{array}{c}\text { Lower-middle-income } \\
\text { countries } \\
(\%)\end{array}$ & $\begin{array}{c}\text { Upper middle-income } \\
\text { countries } \\
(\%)\end{array}$ & $\begin{array}{c}\text { High-income } \\
\text { countries } \\
(\%) \\
\end{array}$ \\
\hline $\begin{array}{l}\text { Governmental recognition of CKD } \\
\text { as a health priority }\end{array}$ & 59 & 50 & 17 & 29 \\
\hline Government funds all aspects of CKD care & 13 & 21 & 40 & 53 \\
\hline $\begin{array}{l}\text { Availability of CKD management and referral g } \\
\text { (international, national, or regional) }\end{array}$ & 46 & 73 & 83 & 97 \\
\hline Existence of current CKD detection programs & 6 & 24 & 24 & 32 \\
\hline Availability of dialysis registries & 24 & 48 & 72 & 89 \\
\hline $\begin{array}{l}\text { Availability of academic centers for renal clinica } \\
\text { trial management }\end{array}$ & 12 & 34 & 62 & 63 \\
\hline
\end{tabular}

CKD, chronic kidney disease.

Data from Bello et al. ${ }^{4}$ 
where racial/ethnic minority groups and people of low socioeconomic status carry a high burden of disease. Extensive data have demonstrated that racial and ethnic minorities (e.g., African Americans in the United States, Aboriginal groups in Canada and Australia, Indo-Asians in the United Kingdom, and others) are affected disproportionately by advanced and progressive kidney disease. ${ }^{10-12}$ The associations of socioeconomic status and risk of progressive CKD and eventual kidney failure also have been well described, with persons of lower socioeconomic status bearing the greatest burden. ${ }^{13,14}$

Recent works have associated apolipoprotein L1 risk variants ${ }^{15,16}$ with increased kidney disease burden among persons with African ancestry. In Central America and Southeastern Mexico, Mesoamerican nephropathy (also referred to as CKD of unknown causes) has emerged as an important cause of kidney disease. While multiple exposures have been studied for their potential role in CKD of unknown causes, recurrent dehydration and heat stress are common denominators in most cases. ${ }^{17}$ Other perhaps more readily modifiable risk factors for kidney disease and CKD progression that disproportionately affect socially disadvantaged groups also have been identified, including disparate rates and poor control of clinical risk factors such as diabetes and hypertension, as well as lifestyle behaviors.

Diabetes is the leading cause of advanced kidney disease worldwide..$^{18}$ In 2016, 1 in 11 adults worldwide had diabetes and more than $80 \%$ were living in low- and middle-income countries ${ }^{19}$ where resources for optimal care are limited. Hypertension is also estimated to affect 1 billion persons worldwide ${ }^{20}$ and is the second leading attributed cause of CKD. ${ }^{18}$ Hypertension control is important for slowing CKD progression and decreasing mortality risk among persons with or without CKD. Hypertension is present in more than $90 \%$ of persons with advanced kidney disease, ${ }^{18}$ yet racial/ethnic minorities and lowincome persons with CKD who live in high-income countries have poorer blood pressure control than their more socially advantaged counterparts. ${ }^{21}$

Lifestyle behaviors, including dietary patterns, are strongly influenced by socioeconomic status. In recent years, several healthful dietary patterns have been associated with favorable CKD outcomes. ${ }^{22}$ Low-income persons often face barriers to healthful eating that may increase their risk of kidney disease. ${ }^{23-25}$ People of low socioeconomic status often experience food insecurity (i.e., limited access to affordable nutritious foods), which is a risk factor for $\mathrm{CKD}^{26}$ and progression to kidney failure. ${ }^{27}$ In lowincome countries, food insecurity may lead to undernutrition and starvation, which has implications for the individual and, in the case of women of child-bearing age, could lead to their children having low birth weight and related sequelae, including CKD. ${ }^{28}$ Rates of undernourishment are as high as $35 \%$ or more in countries such as Haiti, Namibia, and Zambia. ${ }^{29}$ However, in high-income countries, food insecurity is associated with overnutrition, and persons with food insecurity have increased risk of overweight and obesity. ${ }^{30,31}$ Further, food insecurity has been associated with several diet-related conditions, including diabetes and hypertension.

\section{Acute kidney injury}

AKI is an underdetected condition that is estimated to occur in $8 \%$ to $16 \%$ of hospital admissions $^{32}$ and is now well established as a risk factor for CKD. ${ }^{33}$ Disparities in AKI risk are also common, following a pattern similar to that observed in persons with CKD. ${ }^{34}$ AKI related to nephrotoxins, alternative (traditional) medicines, infectious agents, and hospitalizations and related procedures are more pronounced in lowincome and lower-middle-income countries and contribute to increased risk of mortality and CKD in those settings. ${ }^{35}$ Importantly, the majority of annual AKI cases worldwide ( $85 \%$ of more than 13 million cases) are experienced in low-income and lower-middle-income countries, leading to 1.4 million deaths. ${ }^{36}$

\section{Health policies and financing of kidney disease care}

Because of the complex and costly nature of kidney disease care, its provision is tightly linked with the public policies and financial status of individual countries. For example, gross domestic product is correlated with lower dialysis-to-transplantation ratios, suggesting greater rates of kidney transplantation in more financially solvent nations. In several high-income countries, universal health care is provided by the government and includes CKD and ESRD care. In other countries, such as the United States, ESRD care is publicly financed for citizens; however, optimal treatment of CKD and its risk factors may not be accessible for persons 
lacking health insurance, and regular care of undocumented immigrants with kidney disease is not covered. ${ }^{37}$ In low-income and lower-middleincome countries, neither CKD nor ESRD care may be publicly financed, and CKD prevention efforts are often limited. In several such countries, collaborations between public and private sectors have emerged to provide funding for RRT. For example, in Karachi, Pakistan, a program of dialysis and kidney transplantation through joint community and government funding has existed for more than 25 years. ${ }^{38}$

In many settings, persons with advanced CKD who have no or limited public or private sector funding for care shoulder a substantial financial burden. A systematic review of 260 studies including patients from 30 countries identified significant challenges, including fragmented care of indeterminate duration, reliance on emergency care, and fear of catastrophic life events because of diminished financial capacity to withstand them. ${ }^{39}$ Authors of another study conducted in Mexico found that patients and families were burdened with having to navigate multiple health and social care structures, negotiate treatments and costs, finance their health care, and manage health information. ${ }^{40}$ Challenges may be even greater for families of children with ESRD, because many regions lack qualified pediatric care centers.

\section{Organization and structures for kidney disease care}

The lack of recognition and therefore the absence of a global action plan for kidney disease partly explains the substantial variation in structures and capacity for kidney care around the globe. This situation has resulted in variations in government priorities, health care budgets, care structures, and human resource availability. ${ }^{41}$ Effective and sustainable advocacy efforts are needed at global, regional, and national levels to get kidney disease recognized and placed on the global policy agenda.

In 2017, the International Society of Nephrology collected data on country-level capacity for kidney care delivery using a survey, the Global Kidney Health Atlas, ${ }^{4}$ which aligned with the WHO's building blocks of a health system. The Global Kidney Health Atlas highlights limited awareness of kidney disease and its consequences and persistent inequities in resources required to tackle the burden of kidney disease across the globe. For example,
CKD was recognized as a health care priority by government in only $36 \%$ of countries that participated in this survey. The priority was inversely related to income level: CKD was a health care priority in more than half of lowincome and lower-middle-income countries but in less than $30 \%$ of upper-middle-income and highincome countries.

Regarding capacity and resources for kidney care, many countries still lack access to basic diagnostics, a trained nephrology workforce, universal access to primary health care, and RRT technologies. Low-income and lower-middleincome countries, especially in Africa, had limited services for the diagnosis, management, and monitoring of CKD at the primary care level, with only $12 \%$ having serum creatinine measurement, including estimated glomerular filtration rate. Twenty-nine percent of low-income countries had access to qualitative urinalysis using urine test strips; however, no low-income country had access to urine albumin-to-creatinine ratio or urine protein-to-creatinine ratio measurements at the primary care level. Across all world countries, availability of services at the secondary/tertiary care level was considerably higher than at the primary care level (Figure 1 $a$ and $b$ ).,42

\section{Renal replacement therapies}

The distribution of RRT technologies varied widely. On the surface, all countries reported having long-term hemodialysis services, and more than $90 \%$ of countries reported having short-term hemodialysis services. However, access to and distribution of RRT across countries and regions was highly inequitable, often requiring prohibitive out-of-pocket expenditure, particularly in low-income regions. For instance, more than $90 \%$ of upper-middle-income and high-income countries reported having chronic peritoneal dialysis services, whereas these services were available in $64 \%$ and $35 \%$ of lowincome and lower-middle-income countries, respectively. In comparison, acute peritoneal dialysis had the lowest availability across all countries. More than $90 \%$ of upper-middleincome and high-income countries reported having kidney transplant services, with more than $85 \%$ of these countries reporting both living and deceased donors as the organ source. As expected, low-income countries had the lowest availability of kidney transplant services, with only $12 \%$ reporting availability, and live donors as the only source. 


\section{Workforce for kidney care}

Considerable international variation was also noted in the distribution of the kidney care workforce, particularly nephrologists. The lowest density ( $<5$ nephrologists per million population) was very common in low-income countries, whereas the highest density ( $>15$ nephrologists per million population) was reported mainly in high-income countries (Figure 2). ${ }^{4,43,44}$ Most countries reported nephrologists as primarily responsible for both CKD and AKI care. Primary care physicians had more responsibility for
CKD care than for AKI care, as $64 \%$ of countries reported that primary care physicians are primarily responsible for CKD care and $35 \%$ reported that they are responsible for AKI care. Intensive care specialists were primarily responsible for AKI in $75 \%$ of countries, likely because AKI is typically treated in hospitals. However, only $45 \%$ of low-income countries reported that intensive care specialists were primarily responsible for AKI, compared with $90 \%$ of high-income countries; this discrepancy may be due to a general shortage of intensive care

FIGURE 1. Health care services for identification and management of chronic kidney disease by country income level

(a)

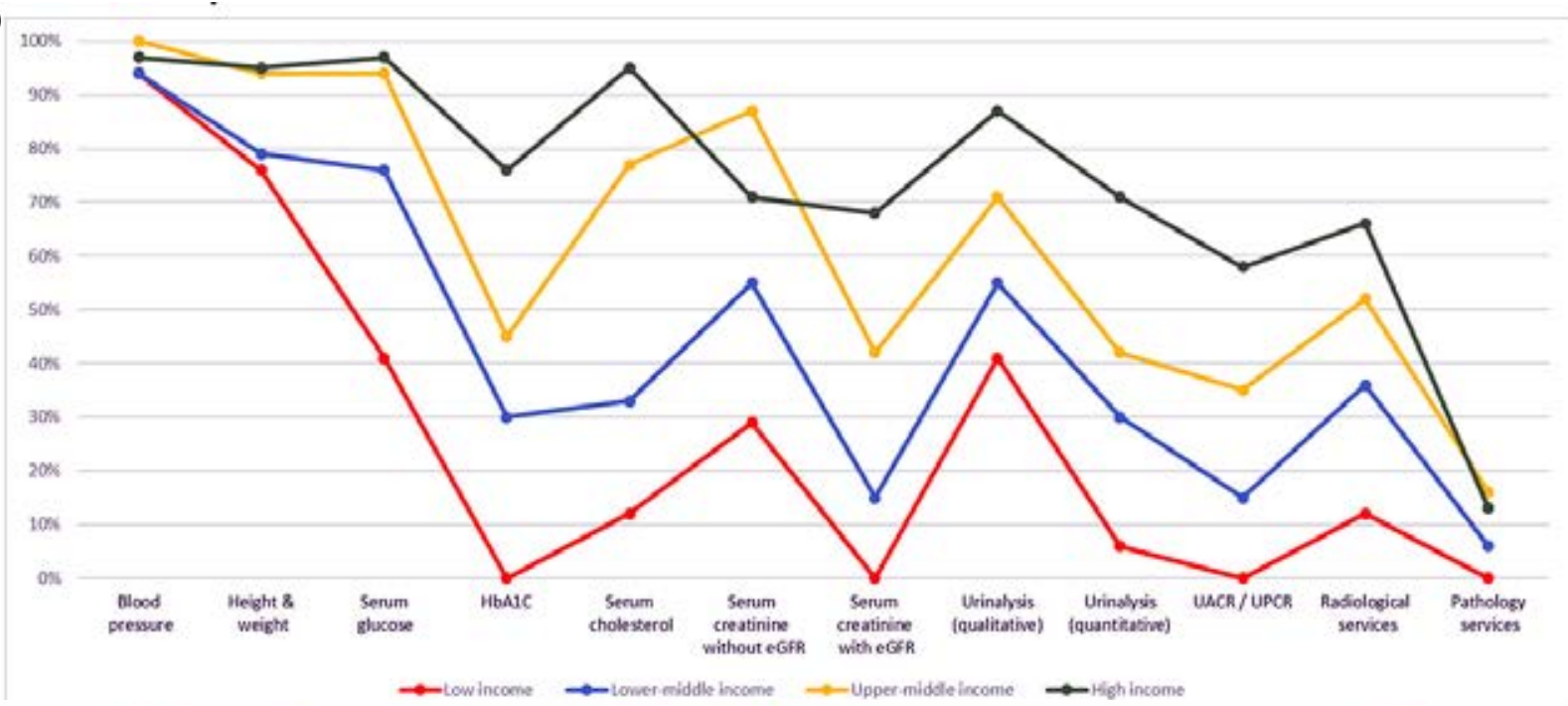

(b)

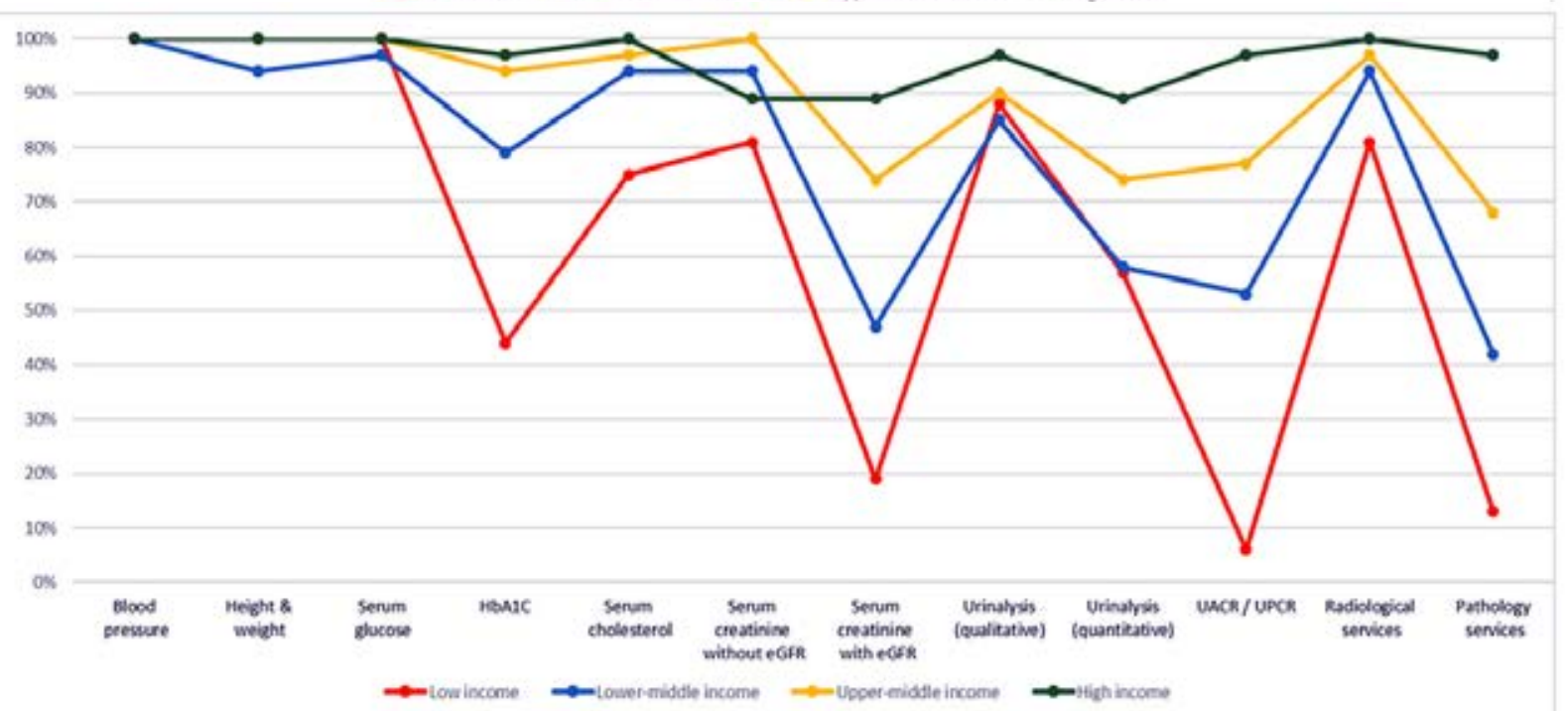

(a) Primary care (i.e., basic health facilities at community levels [e.g., clinics, dispensaries, and small local hospitals]).

(b) Secondary / specialty care (i.e., health facilities at a level higher than primary care [e.g., clinics, hospitals, and academic centers]). eGFR, estimated glomerular filtration rate; $\mathrm{HbA1C}$, glycated hemoglobin; UACR, urine albumin-to-creatinine ratio; UPCR, urine protein-to-creatinine ratio.

Data from Bello et al. ${ }^{4}$ and Htay et al. ${ }^{42}$ 
specialists in low-income countries.

The appropriate number of nephrologists in a country depends on many factors, including need, priority, and resources, and as such there is no global standard with respect to nephrologist density. Regardless, the demonstrated low density in low-income countries calls for concern as nephrologists are essential to provide leadership in kidney disease care, and a lack of nephrologists may result in adverse consequences for policy and practice. However, it is quite encouraging that the number of nephrologists and nephropathologists is rising in low-income and lower-middle-income countries, in part thanks to fellowship programs supported by international nephrology organizations. ${ }^{45}$ It is important to note that the role of a nephrologist may differ depending on how the health care system is structured. The density statistic merely represents the number of nephrologists per million population and provides no indication of the adequacy to meet the needs of the population or quality of care, which depends on volume of patients with kidney disease and other workforce support (e.g., availability of multidisciplinary teams).

For other care providers essential for kidney care, international variations exist in distribution (availability and adequacy). Overall, provider shortages were highest for renal pathologists, vascular access coordinators, and dietitians (with $86 \%, 81 \%$, and $78 \%$ of countries reporting a shortage, respectively), and the shortages were more common in low-income countries. Few countries $(35 \%)$ reported a shortage in laboratory technicians. This information highlights significant inter- and intra-regional variability in the current capacity for kidney care across the world. Important gaps in awareness, services, workforce, and capacity for optimal care delivery were identified in many countries and regions. ${ }^{4}$ The findings have implications for

FIGURE 2. Nephrologist availability (density per million population) compared with physician, nursing, and pharmaceutical personnel availability by country income level

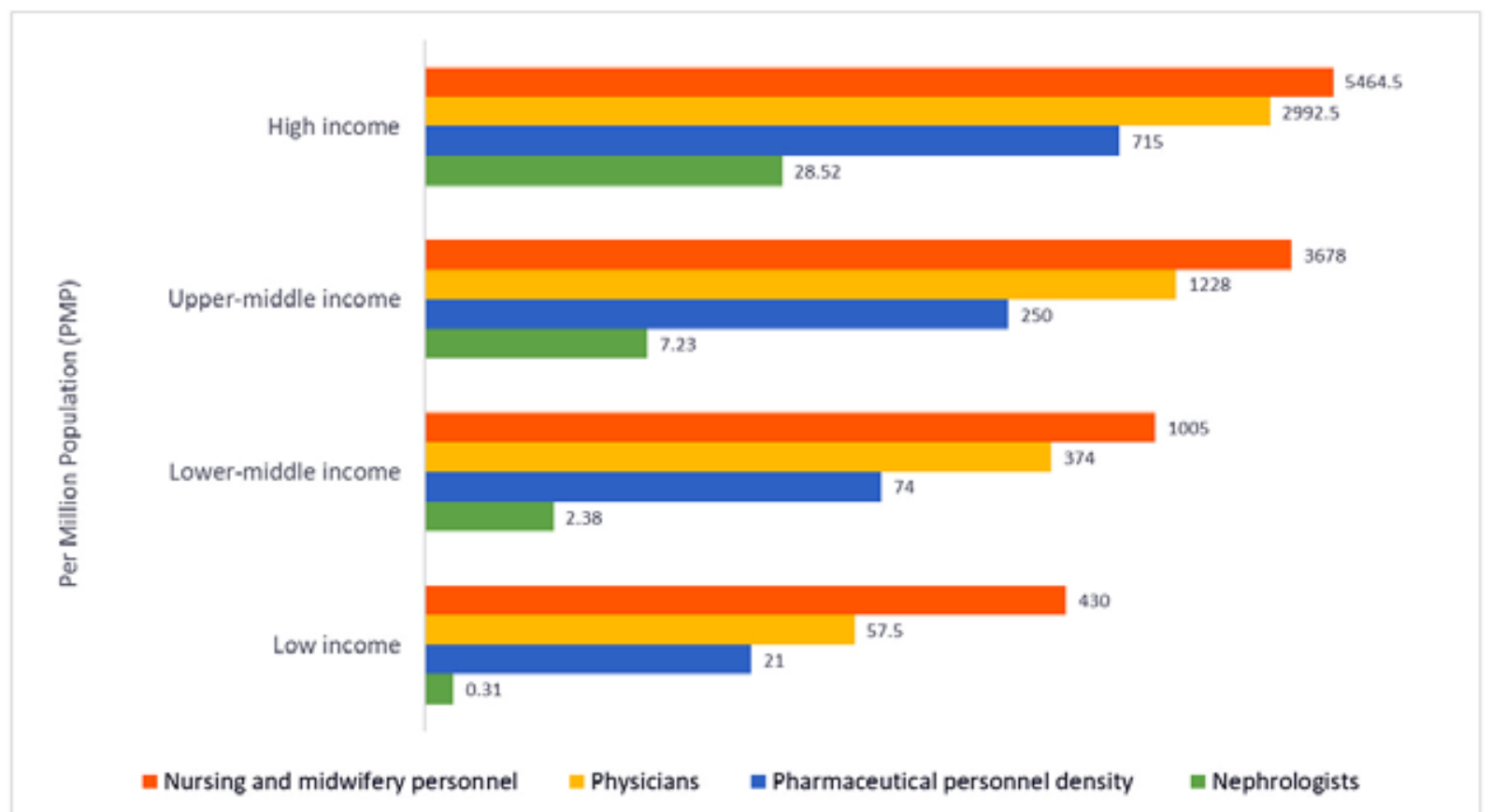

Pharmaceutical personnel include pharmacists, pharmaceutical assistants, and pharmaceutical technicians. Nursing and midwifery personnel include professional nurses, professional midwives, auxiliary nurses, auxiliary midwives, enrolled nurses, enrolled midwives, and related occupations such as dental nurses. A logarithmic scale was used for the $x$-axis $[\log (x+1)]$ because of the large range in provider density.

Data from Bello et al., ${ }^{4}$ Osman et al., ${ }^{43}$ and the World Health Organization (for pharmaceutical personnel: http:/ / apps.who.int/ gho/data/view.main.PHARMS and http:/ / apps.who.int/gho/ data/node.main-amro.HWF?lang=en, for nursing and midwifery personnel:http:/ / apps.who.int/gho/data/view.main.NURSES, for physicians:http:/ / apps.who.int/gho/data/view.main.92000). ${ }^{44}$ 
policy development with regard to establishment of robust kidney care programs, particularly for low-income and lower-middle-income countries. ${ }^{46}$ The Global Kidney Health Atlas has therefore provided a baseline understanding of where countries and regions stand with respect to several domains of the health system, thus allowing the monitoring of progress through the implementation of various strategies aimed at achieving equitable and quality care for the many patients with kidney disease across the globe.

How could this information be used to mitigate existing barriers to kidney care? First, basic infrastructure for services must be strengthened at the primary care level for early detection and management of AKI and CKD across all countries. ${ }^{46}$ Second, although optimal kidney care obviously should emphasize prevention to reduce adverse consequences of kidney disease at the population level, countries (particularly low-income and lower-middleincome countries) should be supported at the same time to adopt more pragmatic approaches in providing RRT. For example, acute peritoneal dialysis could be an attractive modality for AKI, because this type of dialysis is as effective as hemodialysis, requires far less infrastructure, and can be performed with solutions and catheters adapted to local resources. ${ }^{47}$ Third, kidney transplantation should be encouraged through increased awareness among the public and political leaders across countries, because this is the clinically optimal modality of RRT and it is also cost-effective, provided that costs of the surgery and long-term medication and follow-up are made sustainable through public (and / or private) funding. ${ }^{48}$ Currently, most kidney transplants are conducted in high-income countries in part because of lack of resources and knowledge in low-income and lower-middleincome countries, as well as cultural practices and absence of legal frameworks governing organ donation..$^{48}$

\section{CONCLUSION}

Socially disadvantaged persons experience a disproportionate burden of kidney disease worldwide. The provision and delivery of kidney care varies widely across the world. Achieving universal health coverage worldwide by 2030 is one of the WHO Sustainable Development Goals. Although universal health coverage may not include all elements of kidney care in all countries (because this is usually a function of political, economic, and cultural factors), understanding what is feasible and important for a country or region with a focus on reducing the burden and consequences of kidney disease would be an important step toward achieving kidney health equity.

\section{Acknowledgments}

The authors thank the Global Kidney Health Atlas Team, M. Lunney, and M.A. Osman.

\section{APPENDIX}

Members of the World Kidney Day Steering Committee are Philip Kam Tao Li, Guillermo Garcia-Garcia, Sharon Andreoli, Deidra Crews, Kamyar Kalantar-Zadeh, Charles Kernahan, Latha Kumaraswami, Gamal Saadi, and Luisa Strani.

\section{REFERENCES}

1. GBD 2015 DALYs and HALE Collaborators. Global, regional, and national disability-adjusted life-years (DALYs) for 315 diseases and injuries and healthy life expectancy (HALE), 1990-2015: a systematic analysis for the Global Burden of Disease Study 2015. Lancet. 2016; 388(10053):1603-58.

2. Hill NR, Fatoba ST, OkeJL, Hirst JA, et al. Global prevalence of chronic kidney disease - a systematic review and metaanalysis. PLoS One. 2016; 11(7):e0158765.

3. Crews DC, Liu Y, Boulware LE. Disparities in the burden, outcomes, and care of chronic kidney disease. Curr Opin Nephrol Hypertens. 2014; 23(3):298-305.

4. Bello AK, Levin A, Tonelli M, Okpechi IG, et al. Global Kidney Health Atlas: a report by the International Society of Nephrology on the current state of organization and structures for kidney care across the globe. 2017. [Accessed on: August22, 2018]. Available at: https: / / www. theisn.org/images/ISN_advocacy/GKHAtlas_Linked_ Compressed1.pdf

5. Stanifer JW, Jing B, Tolan S, Helmke N, et al. The epidemiology of chronic kidney disease in sub-Saharan Africa: a systematic review and meta-analysis. Lancet Glob Health. 2014; 2(3):e174-81.

6. Davids MR, Eastwood JB, Selwood NH, Arogundade FA, et al. A renal registry for Africa: first steps. Clin Kidney J. 2016; 9(1):162-7.

7. GBD 2015 Mortality and Causes of Death Collaborators. Global, regional, and national life expectancy, all-cause mortality, and cause-specific mortality for 249 causes of death, 1980-2015: a systematic analysis for the GlobalBurden of Disease Study 2015. Lancet. 2016; 388(10053):1459-544.

8. Liyanage T, Ninomiya T, Jha V, Neal B, et al. Worldwide access to treatment for end-stage kidney disease: a systematic review. Lancet. 2015; 385(9981):1975-82.

9. Mehta RL, Cerdá J, Burdmann EA, Tonelli M, et al. International Society of Nephrology's 0by25 initiative for acute kidney injury (zero preventable deaths by 2025): a human rights case for nephrology. Lancet. 2015; 385(9987):2616-43.

10. Samuel SM, Palacios-Derflingher L, Tonelli M, Manns B, et al. Association between First Nations ethnicity and progression to kidney failure by presence and severity of albuminuria. CMAJ. 2014; 186(2):E86-94. 
11. Nicholas SB, Kalantar-Zadeh K, Norris KC. Racial disparities in kidney disease outcomes. Semin Nephrol. 2013; 33(5):409-15.

12. van den Beukel TO, de Goeij MC, Dekker FW, Siegert CE, et al. Differences in progression to ESRD between black and white patients receiving predialysis care in a universal health care system. Clin J Am Soc Nephrol. 2013; 8(9):1540-7.

13. Crews DC, Gutierrez OM, Fedewa SA, Luthi JC, et al. Low income, community poverty and risk of end stage renal disease. BMC Nephrol. 2014; 15:192.

14. Garrity BH, Kramer H, Vellanki K, Leehey D, et al. Time trends in the association of ESRD incidence with arealevel poverty in the US population. Hemodial Int. 2016; 20(1):78-83.

15. Parsa A, Kao WH, Xie D, Astor BC, et al. APOL1 risk variants, race, and progression of chronic kidney disease. N Engl J Med. 2013; 369(23):2183-96.

16. Peralta CA, Bibbins-Domingo K, Vittinghoff E, Lin F, et al. APOL1 genotype and race differences in incident albuminuria and renal function decline. J Am Soc Nephrol. 2016; 27(3):887-93.

17. Correa-Rotter R. Mesoamerican nephropathy or chronic kidney disease of unknown origin. In: García- García G, Agodoa LY, Norris KC (eds). Chronic Kidney Disease in Disadvantaged Populations. Cambridge, MA: Academic Press; 2017.Pag.221-8.

18. Levin A, Stevens PE, Bilous RW, Lamb E, et al. Kidney Disease: Improving Global Outcomes (KDIGO) CKD Work Group. KDIGO 2012 clinical practice guideline for the evaluation and management of chronic kidney disease. Kidney Int Suppl. 2013; 3:1-150.

19. Chan JC, Gregg EW, Sargent J, Horton R. Reducing global diabetes burden by implementing solutions and identifying gaps: a Lancet Commission. Lancet. 2016; 387(10027):1494-5.

20. Kearney PM, Whelton M, Reynolds K, Muntner P, et al. Global burden of hypertension: analysis of worldwide data. Lancet. 2005; 365(9455):217-23.

21. Plantinga LC, Miller ER 3rd, Stevens LA, Sara R, et al. Blood pressure control among persons without and with chronic kidney disease: US trends and risk factors 19992006. Hypertension. 2009; 54(1):47-56.

22. Banerjee T, Liu Y, Crews DC. Dietary patterns and CKD progression. Blood Purif. 2016; 41(1-3):117-22.

23. Johnson AE, Boulware LE, Anderson CA, Chit-ua-aree T, et al. Perceived barriers and facilitators of using dietary modification for CKD prevention among African Americans of low socioeconomic status: a qualitative study. BMC Nephrol. 2014; 15:194.

24. Crews DC, Kuczmarski MF, Miller ER3rd, Zonderman AB, et al. Dietary habits, poverty, and chronic kidney disease in an urban population. J Ren Nutr. 2015; 25(2):103-10.

25. Suarez JJ, Isakova T, Anderson CA, Boulware LE, et al. Food access, chronic kidney disease, and hypertension in the U.S. Am J Prev Med. 2015; 49(6):912-20.

26. Crews DC, Kuczmarski MF, Grubbs V, Hedgeman E, et al. Effect of food insecurity on chronic kidney disease in lower-income Americans. Am J Nephrol. 2014; 39(1):27-35.

27. Banerjee T, Crews DC, Wesson DE, Dharmarajan S, et al. Food insecurity, CKD, and subsequent ESRD in US adults. Am J Kidney Dis. 2017; 70(1):38-47.

28. Piccoli GB, Alrukhaimi M, Liu ZH, Zakharova E, et al. Women and kidney disease: reflections on World Kidney Day 2018. Kidney Int. 2018; 93(2):278-83.

29. Food and Agriculture Organization of the United Nations. TheFAOhunger map 2015. [Accessed on: August22, 2018]. Available at: www.fao.org/3/a-i4674e.pdf

30. Shariff ZM, Khor GL. Obesity and household food insecurity: evidence from a sample of rural households in Malaysia. Eur J Clin Nutr. 2005; 59(9):1049-58.

31. Popkin BM. Contemporary nutritional transition: determinants of diet and its impact on body composition. Proc Nutr Soc. 2011; 70(1):82-91.

32. Sawhney S, Marks A, Fluck N, Levin A, et al. Intermediate and long-term outcomes of survivors of acute kidney injury episodes: a large population-based cohort study. Am J Kidney Dis. 2017; 69(1):18-28.

33. Heung M, Steffick DE, Zivin K, Gillespie BW, et al. Acute kidney injury recovery pattern and subsequent risk of CKD: an analysis of Veterans Health Administration data. Am J Kidney Dis. 2016; 67(5):742-52.

34. Grams ME, Matsushita K, Sang Y, Estrella MM, et al. Explaining the racial difference in AKI incidence. J Am Soc Nephrol. 2014; 25(8):1834-41.

35. Luyckx VA, Tuttle KR, Garcia-Garcia G, Gharbi MB, et al. Reducing major risk factors for chronic kidney disease. Kidney Int Suppl (2011). 2017; 7(2):71-87.

36. Lewington AJ, Cerda J, Mehta RL. Raising awareness of acute kidney injury: a global perspective of a silent killer. Kidney Int. 2013; 84(3):457-67.

37. Cervantes L, TuotD, Raghavan R, Linas S, et al. Association of emergency-only vs standard hemodialysis with mortality and health care use among undocumented immigrants with end-stage renal disease. JAMA Intern Med. 2018; 178(2):188-95.

38. Rizvi SA, Naqvi SA, Zafar MN, Akhtar SF. A kidney transplantation model in a low-resource country: an experience from Pakistan. Kidney Int Suppl (2011). 2013; 3(2):236-40.

39. Roberti J, Cummings A, Myall M, Harvey J, et al. Work of being an adult patient with chronic kidney disease: a systematic review of qualitative studies. BMJ Open. 2018; 8(9):e023507.

40. Kierans C, Padilla-Altamira C, Garcia-Garcia G, IbarraHernández M, Mercado FJ. When health systems are barriers to health care: challenges faced by uninsured Mexican kidney patients. PLoS One. 2013; 8(1):e54380.

41. Murray CJ, Frenk J. A framework for assessing the performance of health systems. Bull World Health Organ. 2000; 78(6):717-31.

42. Htay H, Alrukhaimi M, Ashuntantang GE, Bello AK, et al. Global access of patients with kidney disease to health technologies and medications: findings from the Global Kidney Health Atlas project. Kidney Int Suppl (2011). 2018; 8(2):6-73.

43. Osman MA, Alrukhaimi M, Ashuntantang GE, BellorinFont E, et al. Global nephrology workforce: gaps and opportunities toward a sustainable kidney care system. Kidney Int Suppl (2011). 2018; 8(2):52-63.

44. World Health Organization. Global Health Observatory indicator views. [Accessed August 22, 2018]. Available at: http:/ / apps.who.int/gho/data/ node.imr

45. Harris DC, Dupuis S, Couser WG, Feehally J. Training nephrologists from developing countries: does it have a positive impact? Kidney Int Suppl (2011). 2012; 2(3):275-8.

46. Couser WG, Remuzzi G, Mendis S, Tonelli M. The contribution of chronickidney disease to the global burden of major noncommunicable diseases. Kidney Int. 2011; 80(12):1258-70.

47. Chionh CY, Soni SS, Finkelstein FO, Ronco C, Cruz DN. Use of peritoneal dialysis in AKI: a systematic review. Clin J Am Soc Nephrol. 2013; 8(10):1649-60.

48. Muralidharan A, White S. The need for kidney transplantation in low- and middle-income countries in 2012: an epidemiological perspective. Transplantation. 2015; 99(3):476-8. 